\title{
Interfacial debonding force and shear strength of sugar palm (Arenga pinnata) fiber reinforced composites by pull-out test
}

\begin{abstract}
An experimental investigation was performed to understand the pulling out behaviour of sugar palm (Arenga pinnata) fibers from unsaturated polyester (UP) composites. The effect of embedded length on the fiber-matrix interface was studied. Fibers were treated with UP and phenol formaldehyde (PF). Untreated fibers were used as the control. Single fiber pull-out tests were carried out for 360 specimens to determine the debonding force and interfacial shear strength (IFSS). Significant increase in debonding force of untreated fiber and UPimpregnated fiber was observed from embedded length of $2 \mathrm{~mm}$ to $3 \mathrm{~mm}$. However, no significant increase was observed for the embedded length of more than $3 \mathrm{~mm}$. Debonding force showed remarkable improvement with ascending order of untreated fibers, PFimpregnated fibers, and UP-impregnated fibers. The optimum embedded lengths of untreated fibers and UP fibers were determined. Additional finding showed that the interfacial shear strength decreased as the embedded length increased. However, UP-impregnated fibers showed the highest IFSS value, followed by PF fibers and untreated fibers. Analysis using Scanning Electron Microscope (SEM) was also included to justify the result.
\end{abstract}

Keyword: Debonding force; Interfacial shear strength; Optimum embedded length; Single fiber pull-out test 